\title{
NANOSIZE SCALE ADDITIVES MIX INFLUENCE ON THE PROPERTIES OF THE HIGH PERFORMANCE CONCRETES
}

\author{
Dr Andrey Ponomarev* \\ St.Petersburg State Polytechnical University, St.Petersburg, Russia \\ Dr Miloš Knezević \\ University of Montenegro, Podgorica, Montenegro \\ Dr Nikolay Vatin \\ St.Petersburg State Polytechnical University, St.Petersburg, Russia \\ Svetlana Kiski \\ St.Petersburg State Polytechnical University, St.Petersburg, Russia \\ Ilya Ageev \\ St.Petersburg State University, St.Petersburg, Russia
}

It was experimentally founded, that the size and the topology of the active additives particles in the composition of the new kinds of high performance concretes is a very important parameter (as its chemical activity), especially if the combination of these additives enables realization of nonlinear phenomena. The sample which is combination of highly dispersive silica fume and nanocarbon particles of the fulleroid type - Astralenes ${ }^{\circledR}$, was investigated. Also, the possibility to enlarge the lifetime of the polymer components in composite concretes due to the presence of the nanoparticles of fulleroid type was determined.

Key Words: Nanosize scale additives mix, Micro amount of additives, Silica fume, Astralenes $₫$, Optimal structure of the cement stone, Improved mobility of concrete solution, Improved pressure strength, Life-time of polymer components

\section{INTRODUCTION}

A lot of different additives for concrete exist and most of them influence on the strength and the other main concrete parameters, functioning as chemical active components in concrete mixtures $[02,03,07,10,11,13,14,15,16,17]$. Also, for the high performance concretes, a lot of good results have been achieved by using cement that was modified by different modifiers [01]. In same new works even the copper slag was successfully used for improving the property of the concrete [05]. There are not so much information on the dependence between the size and the topology form of the particles of these additives and their efficiency, except for example in the article [06]. The possibility of improving the properties of high performance fine-aggregate concretes (HPC) by using the nanosize scale mix of silica foam and a carbon nanoparticles of fulleroid type - Astralenes $₫$ was investigated in articles $[08,04]$.
Method, experimental results, discussion.

It is well known that the dependence between the catalyzation amount of the silica fume or the carbon nanoparticles and the properties of the concrete mix is not precisely researched, although it is well known that the Astralenes $₫$ influence on the properties of the composite concretes and the synergetic phenomena of mixing the micro disperse additives into concretes have been founded [09, 12]. Our work was dedicated to detail research on the influence of the micro concentration of the active silica dioxide in high disperse form (silica fume) and Astralenes ${ }^{\circledR}$ on the mobility of the high quality fine-aggregate concrete mixture and on the pressure strength of the test specimens made of this concrete. The special high disperse silica fume and Astralenes $\AA$ containing modifier TC 2166-00413800138-2004 in the concentration diapason of 10-2 - 10-5 relatively to total concrete mass was used for this research. The fine-aggregate con- 
crete was made of usually used Portland Cement CEM 42,5, dry river sand $0-0,5 \mathrm{~mm}$ and mix of different doping agents, which amounts and recipe were varied. In the most experimental cases the plasticizer Penta Flow PC-AC and MF 5581 were used. The water-cement ratio usually was in the range $0,25-0,4$. The mobility of the concrete mix was determined as the slump flow of the cone on the shaking table. The pressure strength of the test patterns was measured by the special digital hydroelectric measuring press with the pressure strength range till the 150 tons. The additional grinding of the silica fume have been made in a grinding mill. The grinding mill is the effective grinding equipment for grinding the materials to the ultra disperse powders. The base material was loaded into the special grinding volume of the mill. The steel balls with the diameter 8 - $28.6 \mathrm{~mm}$ were inside the drum. The balls grind up the silica fume for a few hours. The particle size distribution of the silica fume before and after 5 hours of grinding was measured by laser particle size analyzer Mastersizer 2000. Measurements of the sizes of the particles have been made in a wide range between 0.02 and 2000 microns. Because the silica fume is not a very hard material the steel particles were absent into the grinded silica fume.

On the Figure 1 the size distribution for the initial and for the grinded silica fume are shown.

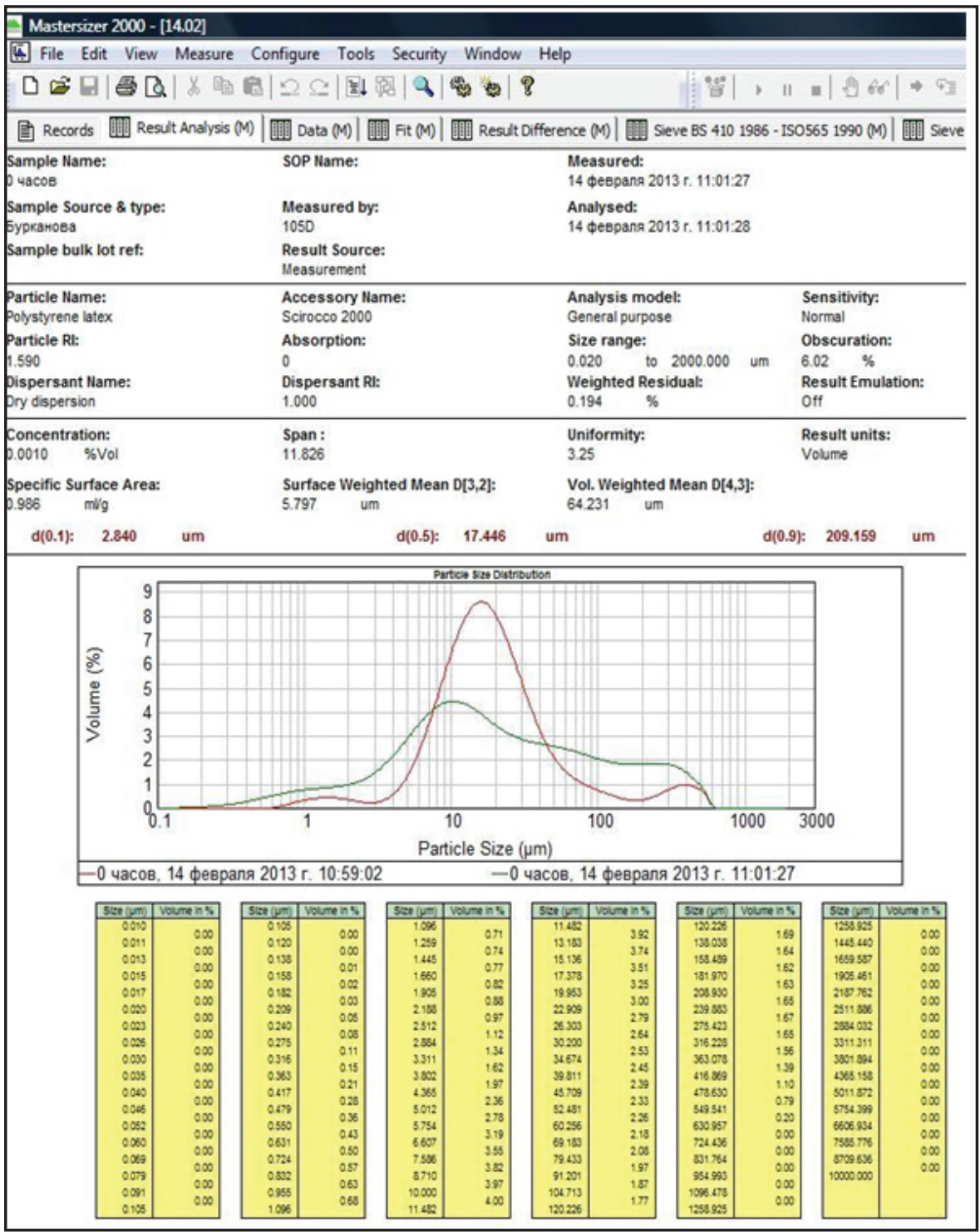

Figure 1: Particle size distribution of the high disperse silica fume after 5 hours of grinding ball drum proces ing and underlying distribution red line - underlying distribution of the high disperse silica fume particles green line - the high disperse silica fume particles distribution after 5 hours of grinding 
As it can be found out from Figure 2, the diapason of the additive concentration $8-30 \mathrm{ml} / \mathrm{l}$ results in nonlinear growth of the mobility of the concrete solution. The fact is, that exactly in this interval the maximum of pressure strength take place.
This phenomena is fixed on the Figure 3. Also in this concentration diapason the phenomena of the nonlinear increasing the mobility of the concrete solution have appeared even without the presence of any plasticizer, as it is possible to be seen on the Figure 4.

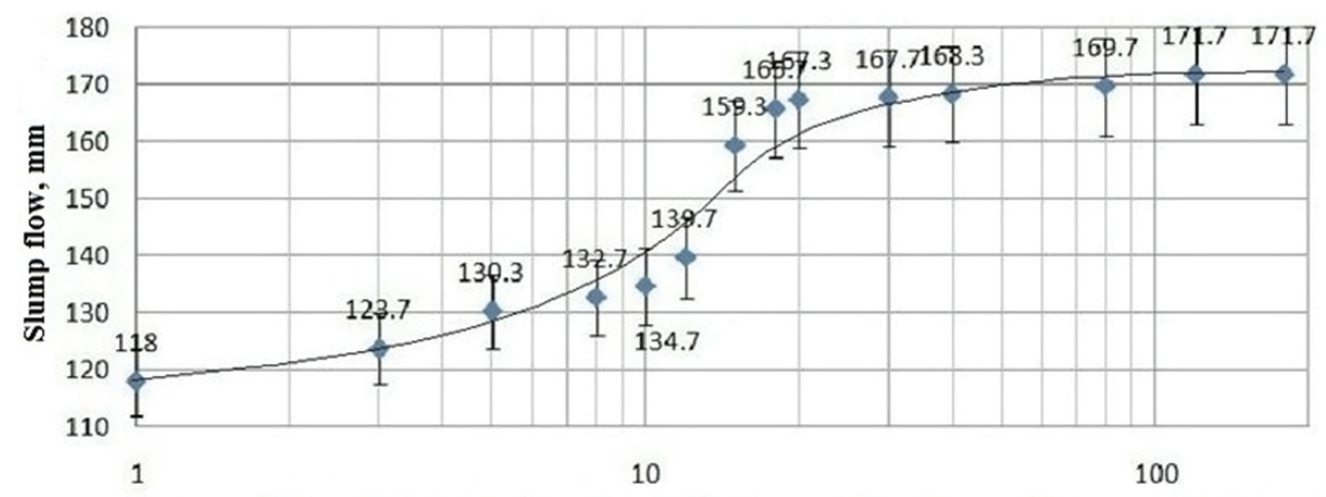

Amount of 5\% colloidal solution of the high disperse silica fume, $\mathrm{ml} / \mathrm{l}$ (concrete mixture)

Figure 2: The micro quantity of the high disperse silica fume influence on the mobility of the modified fine-aggregate concrete mixture with hyperplasticizer MF5581 (0.4\% of cement mass), W/C $=0.4$

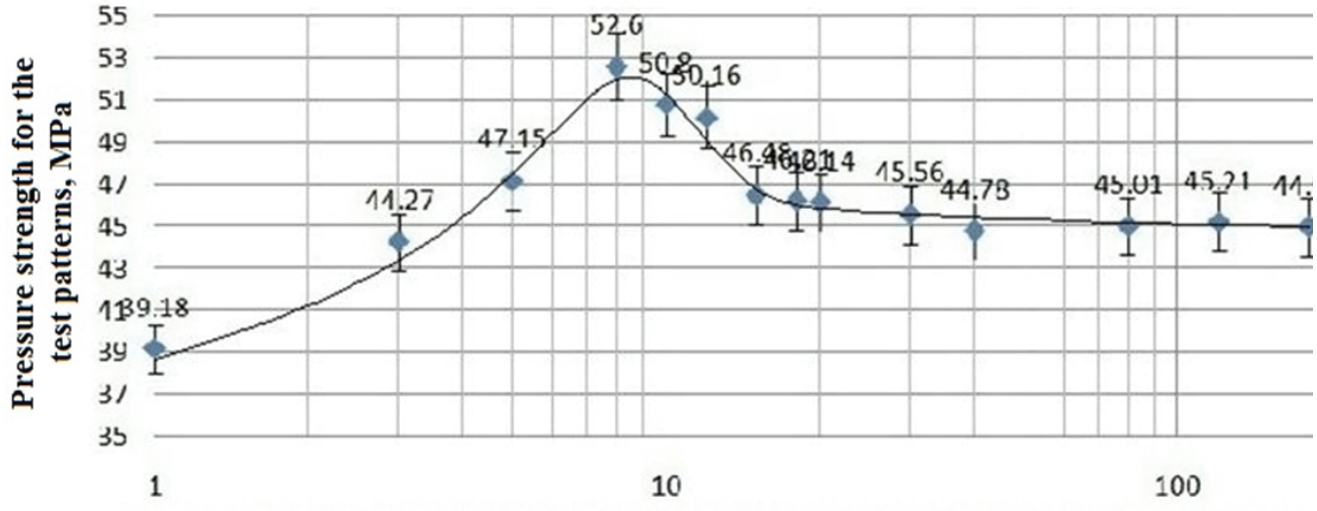

Amount of 5\% colloidal solution of the high disperse silica fume, $\mathrm{ml} / \mathrm{l}$ (concrete mixtul

Figure 3: Micro quantity of the high disperse silica fume influence on the pressure strength of the test specimens made of modified fine-aggregate concrete with hyperplasticizer MF5581 (0.4\% of c ment mass), W C $=0.25$

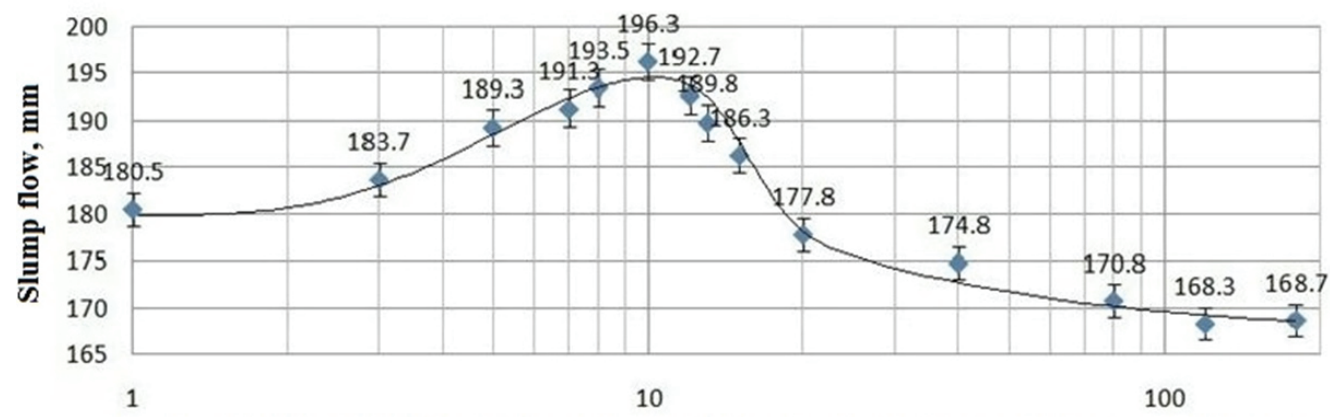

Amount of 5\% colloidal solution of the high disperse silica fume, $\mathrm{ml} / \mathrm{l}$ (concrete mixture)

Figure 4: Micro quantity of the high disperse silica fume influence on the mobility of the concrete solution with $W / C=0.4$ (without any plasticizer) 
By using only Astralenes $®$ (the tor-like structure of Astralenes ${ }^{\circledR}$ is shown on the Figure 5 ), or Astralenes ${ }^{\circledR}$ containing modifiers as fine additive in concrete mixture also lead to increasing the pressure strength of test pattern made of modified concrete, as it is shown on Figure 6.

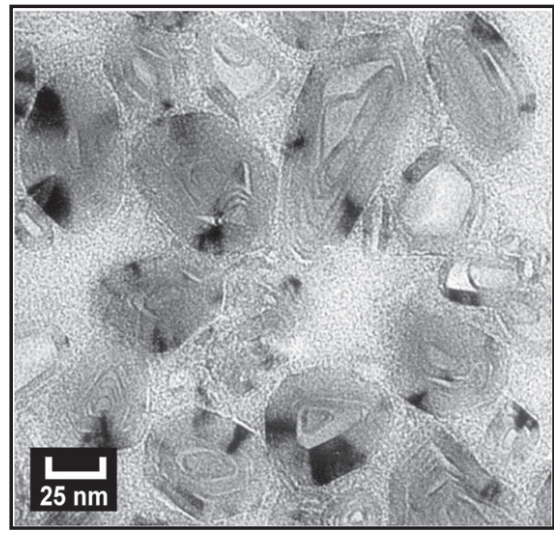

Figure 5: TEM photo of Astralenes ${ }^{\circledR}$

The most biggest increasing of the pressure strength possibly lie in the concentration diapason $6 \times 10^{-4}-6 \times 10^{-5} \%$ of mass. Due to the nonlinear concentration dependences it was possible to find the synergy optimal relation between the amount of high disperse silica fume and amount of the Astralenes ${ }^{\circledR}$.

By using these tools of preparing the new concretes, the light HPC (LHPC) with the density $1500 \mathrm{~g} / \mathrm{cm}^{3}$ (Leopor filler made) have been developed. The LHPC parameters: D1500; opr.= $70 \mathrm{MPa} ; \mathrm{W} 20, \mathrm{~F} 300$ and R6 were reached.
Additionally, the very important phenomena of Astralenes ${ }^{\circledR}$ application in polymer media was founded. Exactly concentration of $6 \times 10^{-4}-6 \times$ $10^{-5} \%$ mass of Astralenes $\circledR$ lead to dumping the thermo-oxidation, photo-oxidation and radiation oxidation destruction of the different polymers, if it may be added to concrete recipes. This is the reason for increasing the life-time of polymerconcretes during its exploitation.

\section{CONCLUSION}

The non-linear dependences of the improvements of the mobility and pressure strength of the fine-aggregates concretes by doping the catalization amount of the nanosize silica fume and tor-like carbon nanoparticles (Astralenes $®$ ) were founded. The level of the maximal mobility improvement of the fine-aggregate concrete mixtures can reach more than $50 \%$, the pressure strength improvement of the modified concrete can reach more than $40 \%$. By using the technology of doping the very small amount of the fine disperse silica fume and same also very small amount of Astralenes $\AA$ containing modifier it is possible to move in practically important branches of building industry and permit to construct the new kind of HPC (including LHPC) with the high levels of its parameters. It is especially important, that a new possibility of increasing the life-time of polymer-concretes have appeared.

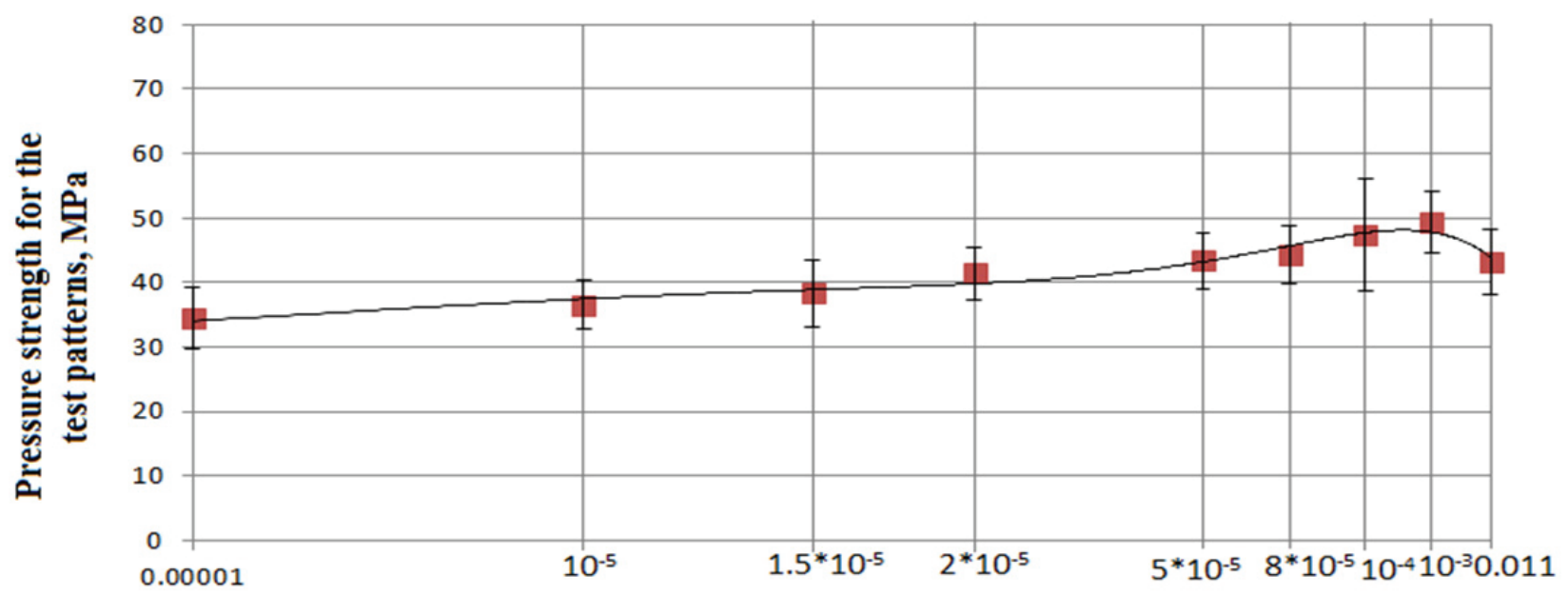

Amount of carbon nanoparticles, \%

Figure 6: Dependence of the pressure strength of the concrete modified by Astralenes ${ }^{\circledR}$ from modifier co centration into the concrete mixture 


\section{SUMMARY}

The task treated in this paper is fulfilled. The limit of the mobility improvement of the researched concrete mixture and the limit of the pressure strength improvement of the concrete were defined. The concentration dependences of these improvements are non-linear and it was possible to determine the intervals of the maximal levels of this improvements. We hope that the results achieved in this research are possible to became a practical tool in building materials science.

\section{REFERENCES}

1) Ayano T., Kuramoto O.and Sakata K. (2000), Concrete with copper slag as fine aggregate, Journal of Society of Material Science Japan, Vol.49 (10), pp. 1097-1102

2) Bajenov U.M.,Lukutcova N.P., Karpikov E.G. (2013), Fine-aggregate concrete have modified by the complex microdisperse additive, Herald of Moscow State Building University, №2, pp. 94-100

3) Batrakov V.G. (1998), Modified concretes, Moskva, Strojizdat

4) Figovsky O., Beilin D., Ponomarev A. (2012), Successful implementation of nanotechnologies in building materials, Nanotechnologies in construction, No. 3 (19), pp. 6-21.

5) Grammond N.J. (1985), Thaumasite in Failed Cement Mortars and Renders from Exposed Brickwork, Cement and Concrete Research, Vol.15, pp. 1039.

6) Halushev A.K. (2012), Exploitation properties of the concretes based on the composite cements have Modified, Modern industrial and civil building construction, Vol.8, №3, pp.149 - 158

7) Kaprielov S., Sheinfeld A. (2000): Influence of Silica Fume-Fly Ash-Superplasticizer Combinations in Powder-Like Complex Modifier on Cement Paste Porosity and Concrete Properties, CANMET/ACI Int. Conf. on Superplasticizers and other Chem. Admixtures in Concrete, Rome, France, Proceedings, pp.383-400.

8) Krivtsov E.E., Nikulin N.M., Yasinskaya E.V. (2011): Research of the parameters of nanomodified dry Mix, Journal of Civil Engineering, №2 (20), pp. 29-32.

9) Kurdovski W. and Nocun-Wozelik (1983),
The Tricalcium Silicane Hydration in the Presence of Active Silica, Cement and Concrete Research, Vol. 13, pp. 341-348.

10) Lazarevska, M., Milanovic, M., Knezevic, M., Cvetkovska, M., Trombeva-Gavriloska, A., Samardzioska, T. (2014): An artificial neural network prediction model for fire resistance of composite columns, Journal of Applied Engineering Science, Vol. 12, № 1, pp 63-68

11) Lazarevska, M., Trombeva-Gavriloska, A., Knezevic, M., Samardzioska, T., Cvetkovska, M. (2012): Neural network prognostic model for RC beams strengthened with CFRP strips, Journal of Applied Engineering Science, № 1 (10), pp. 27-30

12) Matveeva E.G. (2011): Improving the efficient of the concrete by doping the nanodisperse silica fume, Ph.D. work, Belgorod.

13) Murgul, V. (2014): Features of energy efficient upgrade of historic buildings (illustrated with the example of Saint-Petersburg), Journal of Applied Engineering Science, Vol. 12 (1), pp 1-10

14) Nemova, D., Murgul, V., Golik, A., Chizhov, E., Pukhkal, V., Vatin N. (2014): Reconstruction of administrative buildings of the 70s: the possibility of energy modernization, Journal of Applied Engineering Science, Vol. 12 (1), pp 37-44

15) Ponomarev A.N., Nikitin V.A. (2003) Multylayered fulleroid-type polyhedral carbon nanostructures, RU Patent 2196731

16) Ponomarev A.N., Yudovitch M.E. (2009) Torlike form multilayered fulleroid-type carbon nanoparticles, RU Patent 2397950.

17) Stevanović, I., Stanojević, D., Nedić, A. (2013): Setting the after sale process and quality control at car dealerships to the purpose of increasing clients satisfaction, Journal of Applied Engineering Science, 11 (2), pp. 81-88.

Paper sent to revision: 27.05.2014.

Paper ready for publication: 12.09.2014. 